\title{
BARTOLOMÉ DE LAS CASAS Y LOS DERECHOS HUMANOS
}

\author{
Mariano Delgado*
}

\begin{abstract}
Sumario: I. Introducción. II. El derecho de los pueblos amerindios a vivir en libertad (y a la libre aceptación o rechazo del dominio español). III. El derecho de los pueblos amerindios a la resistencia (contra el dominio español, por ser éste desde un principio tiránico). IV. El derecho de los pueblos amerindios al respeto y conservación de sus propias culturas. V. El derecho de los pueblos amerindios al respeto de su religiosidad y a conservar, después de la conversión, los elementos compatibles con el cristianismo. VI. El derecho de los pueblos amerindios a rechazar un cristianismo predicado a la sombra de las armas. VII. Consideraciones finales. VIII. Bibliografía.
\end{abstract}

\section{INTRODUCCIÓN}

Cuando se habla de la Iglesia católica y los derechos humanos se suelen mencionar las dificultades de Roma con la historia moderna de la libertad hasta el cambio de paradigma del Concilio Vaticano II. Ese punto de vista no es toda la verdad, sino más bien fruto de la costumbre de unir los derechos humanos a la lucha por la libertad de conciencia despertada por la reforma protestante, o mejor dicho por algunos disidentes como el español Miguel Servet o el savoyardo Sebastán Castellio. No siempre se ha resaltado en el devenir de los derechos humanos el papel de las discusiones suscitadas por el proceso de conquista y evangelización del Nuevo Mundo, con especial protagonismo

* Doctor por la Universidad de Innsbruck (Austria) y por la Universidad Libre de Berlín (Alemania). Profesor e investigador en la Universidad de Friburgo (Suiza). 
Esta revista forma parte del acervo de la Biblioteca Jurídica Virtual del Instituto de Investigaciones Jurídicas de la UNAM

de la Escuela de Salamanca y Bartolomé de Las Casas, ${ }^{1}$ que querían conducir la cuestión por un camino especialmente importante en nuestros días: el derecho de los pueblos no-europeos a ser considerados como socios en condiciones de igualdad en el mundo globalizado.

En las últimas décadas se ha abierto paso la idea de que también las controversias con motivo de la conquista y evangelización del Nuevo Mundo, en las que papas, teólogos y juristas han defendido los derechos de los pueblos y las personas, independientemente de si eran cristianos o no, merecen un puesto de honor en la historia de los derechos humanos. En este contexto, Bartolomé de las Casas es objeto de una atención especial. ${ }^{2}$ Aunque pensadores de reconocido prestigio internacional, como Immanuel Wallerstein, ven en Las Casas un precursor del auténtico universalismo global tan buscado en nuestros días: es decir, de un universalismo que no sólo expanda

1 Las obras de Las Casas serán citadas según estas ediciones: Las Casas, Bartolomé de, Obras completas, Paulino Castañeda Delgado (ed.), Madrid, Alianza Editorial, 1988-1998, 14 vols. (abreviación: OC con número de volúmen y página); Las Casas, Bartolomé de, Werkauswahl, Mariano Delgado (ed.), Paderborn, Ferdinand Schöningh, 1994-1997, 4 vols. (abreviación: WA con número de volúmen y página).

2 Cfr., por ejemplo, Abril Castelló, Vidal, "Los derechos de las naciones según Bartolomé de las Casas y la Escuela de Salamanca", en Las Casas, OC 6, pp. 15-181; Beuchot, Mauricio, Los fundamentos de los derechos humanos en Bartolomé de las Casas, Barcelona, Antrhopos, 1994; Comisión Nacional para la Conmemoración del V Centenario del Descubrimiento de América, Declaración universal de los derechos humanos. Homenaje a Fray Bartolomé de Las Casas, Sevilla 1484, Madrid, Ministerio de Cultura-Junta de Andalucía, 1984; Galmes, Lorenzo, Bartolomé de las Casas: defensor de los derechos humanos, Madrid, Católica, 1982; Gillner, Matthias, "Bartolomé de Las Casas und die Menschenrechte”, Jahrbuch für Christliche Sozialwissenschaften, Münster, 1998, t. 39, pp. 143-160; Hernández, Ramón, "Francisco de Vitoria y Bartolomé de Las Casas, primeros teorizantes de los derechos humanos", Archivo Dominicano, Salamanca, año IV, 1983, pp. 199-266; Université d'Aix-Marseille et Institut d'Études Politiques, Las Casas et la politique des droits de l'homme, Aix-en-Provence, Institut d'Études Politiques, 1976; Linares Maza, Antonio, Bartolomé de las Casas, un andaluz en el Nuevo Mundo. Desagravio psiquiátrico al primer anticolonialista, precursor de los derechos humanos, Málaga, Arguval, 1993; "Dem Vorkämpfer der Menschenrechte Fray Bartolomé de Las Casas 1566-1966”, Neue Zeitschrift für Missionswissenschaft, año XXII, núm. 3, Immensee, 1966; Pereña, Luciano, La Carta de los derechos humanos según Bartolomé de las Casas, Guatemala, Convento de Santo Domingo, 1978; Pérez Luño, Antonio, "Democracia y derechos humanos en Bartolomé de las Casas. Estudio preliminar al Tratado De Regia Potestate", en Las Casas, OC 12, pp. I-XXXIX; Piepke, Joachim, "Die Frage der Menschenrechte im Amerika des 16. Jahrhunderts", Theologie der Gegenwart, Erfurt, 1990, pp. 20-36; Ruiz Sotelo, Mario, Crítica de la razón imperial. La filosofía política de Bartolomé de Las Casas, México, Fondo de Cultura Económica, 2010; Solís Aznar, Pedro, "Fray Bartolomé de las Casas, precursor de los derechos humanos", Revista de la Universidad de Yucatán, Mérida, año 16, núm. 91, 1974, pp. $15-40$. 
los valores occidentales, sino que preste también atención a los de otras culturas, ${ }^{3}$ todavía es posible que alguien, como María Elvira Roca Barea (en su best seller: Imperiofobia y leyenda negra) se permita este juicio de valor:

Fray Bartolomé no fue ni mucho menos el primero en defender los derechos de los indígenas. Ni el primero ni el mejor, aunque sí el más sensacionalista. Su papel real está completamente desenfocado por su importancia propagandística. Esta aventura fascinante que llevó al reconocimiento de la igualdad de todos los seres humanos ante la ley y al nacimiento del Derecho Internacional la emprendieron hombres mucho más valientes y capaces, que Las Casas. $^{4}$

Por otra parte, algunos autores pretenden descubrir en la obra de Las Casas prácticamente todos los derechos humanos modernos. Otros creen encontrar en Las Casas incluso el terminus technicus "derechos humanos". ${ }^{5}$ Pero, si leemos atentamente la cita, Las Casas no utiliza el término en el sentido actual, sino para señalar los diferentes códigos de derecho humano positivo, a diferencia del derecho natural: "Lo sexto, se suponga que, según las reglas de los derechos humanos, confirmados por la razón y ley natural, y mucho más por la ley de caridad cristiana, algunas veces se admiten o hacen justamente algunas determinaciones y cosas por ciertos respectos y razones que se ofrecen, las cuales, si cesasen, aquéllas con justicia no podrían tolerarse" (OC 10: 236).

Para valorar la contribución real de Bartolomé de las Casas a los derechos humanos debemos partir de la siguiente pregunta: ¿Qué derechos "inalienables" tenían para él los pueblos y las personas del Nuevo Mundo bajo el proceso de conquista y evangelización, de forma que los españoles y demás miembros del orbis christianus estuvieran obligados en conciencia a respetarlos? Las Casas defiende los siguientes "derechos fundamentales" de los pueblos amerindios: 1) El derecho a vivir en libertad (y a la libre

3 Cfr. Wallerstein, Immanuel, European Universalism. The Rhetoric of Power, Nueva York, New Press, 2006.

4 Roca Barea, María Elvira, Imperiofobia y leyenda negra. Roma, Rusia, Estados Unidos y el Imperio español, 10a. ed., pról. de Arcadi Espada, Madrid, Siruela, 2017, p. 319.

5 Cfr. Sievernich, Michael, "460 Jahre Menschenrechte", Stimmen der Zeit, Friburgo (Alemania), vol. 137, 2012, pp. 816-826; id., "“Menschenrechte' in der Frühen Neuzeit", en Delgado, Mariano (ed.), "Ces gens ne sont-ils pas des hommes?" - Evangile et prophétie / "Sind sie etwa keine Menschen?" - Evangelium und prophetie. Colloque de la Faculté de Théologie de Fribourg (1-4 décembre 2011) - Kolloquium der Theologischen Fakultät Freiburg (1.- 4. Dezember 2011), Friburgo, Suiza, Academic Press, 2013, pp. 286-309. 
aceptación o rechazo del dominio español: se trata de un "derecho de autodeterminación" cuando hay un nuevo pactum translationis). 2) El derecho a la resistencia (contra el dominio español, si éste es desde el principio una tiranía, es decir, una usurpación). 3) El derecho al respeto y conservación de sus propias culturas. 4) El derecho al respeto de su religiosidad y a conservar después de la conversión pacífica los elementos compatibles con el cristianismo. 5) El derecho a rechazar un cristianismo predicado a la sombra de las armas. La defensa de dichos derechos convierte a Bartolomé de las Casas en un 'precursor' tanto del Concilio Vaticano II como del mundo postcolonial y globalizado de nuestro tiempo.

\section{EL DERECHO DE LOS PUEBLOS AMERINDIOS A VIVIR EN LIBERTAD (Y A LA LIBRE ACEPTACIÓN O RECHAZO DEL DOMINIO ESPAÑOL)}

Este es un principio fundamental de la teoría política lascasiana, tanto en el contexto general como en el amerindio. En su obra De regia potestate (OC 12: 12-223), aparecida en 1571 en Francfort, después de su muerte, pero escrita sobre 1554, Las Casas nos presenta su teoría política sin ninguna clase de referencia al contexto amerindio, aunque el motivo de fondo para escribirla haya sido el problema de la encomienda. Puede ser que el editor de la obra, el jurista alemán Wolfgang Griesstetter (del que sabemos muy poco, y cuyo nombre puede ser un pseudónimo bajo el que se esconde un desconocido admirador de la teoría política del obispo de Chiapas), ${ }^{6}$ haya suprimido toda referencia al contexto para resaltar el valor universal de su contenido. La lucha por la libertad de los indios se convierte así en una "lucha por el reconocimiento de unos derechos básicos comunes a todos los hombres".? El cantus firmus es la libertad del pueblo y la translación de la soberanía por éste a los reyes en un acto de libre consentimiento de todos los tangidos, sancionado además por un contrato de gobierno entre ambas partes.

6 Cfr. Schmidt, Peer, "Freiheit und Herrschaft in Las Casas De imperatoria vel regia potestate (1571). Eine propagandistische Finte", Jahrbuch für Geschichte Lateinamerikas, Colonia, núm. 39, 2002, pp. 37-50.

7 Pérez-Luño, Antonio, op. cit., p. XXXVIII; cfr. también Delgado, Mariano, "Universalmonarchie, translatio imperii und Volkssouveranität bei Las Casas oder Das prozeßhafte Entstehen einer politischen Theorie zwischen Mittelalter und Neuzeit", en Las Casas, WA 3/1, pp. 161-179; Eggensperger, Thomas, Der Einfluss des Thomas von Aquin auf das politische Denken des Bartolomé de Las Casas im Traktat De imperatoria vel regia potestate. Eine theologisch-politische Theorie zwischen Mittelalter und Neuzeit, Münster, Lit, 2000. 
Para Las Casas, los hombres y los pueblos son libres por naturaleza ( $c f r$. OC 12: 34/35). Con el Digestum, la libertad es para él "más preciosa e inestimable que todas las riquezas que pueda tener un pueblo libre" (OC 12: 82/83). En el Tratado sobre los indios que se han hecho esclavos dice Las Casas con la tradición jurídica que "la libertad de los hombres, después de la vida" es la cosa "más preciosa y estimable" (OC 10: 239), con lo que hace un nexo entre libertad y vida, como lo hará después la declaración de los Estados Unidos sobre los derechos humanos al hablar de "enjoyment of life and liberty". ${ }^{8}$ Y con el Codex, Las Casas considera la libertad "un derecho imprescriptible" (OC 12: 44/45); siempre debe ser presumida, de forma que en caso de duda hay que optar por la libertad (in dubio pro libertate), que "ningún hombre bueno pierde [...] sin perder al mismo tiempo su alma" (OC 12: 38/39, 198).

El pueblo es para Las Casas, en convergencia con las mejores tradiciones del derecho y de la Escuela de Salamanca, "el manantial y origen de todas las potestades y jurisdicciones" (OC 12: 100/101), por lo tanto, también "causa eficiente de todos los reyes" (OC 12: 62/63). De forma expresa, Las Casas se refiere en este contexto a la antigua translatio imperii a populo in principem, cuando escribe, por ejemplo: "el pueblo romano comenzó a transferir al príncipe toda la potestad de imponer cargas" (OC 12: 62/63).

Aunque habla de "toda la potestad", Las Casas no entiende la translatio como un cheque en blanco al estilo, por ejemplo, de Francisco Suárez en la época del absolutismo. ${ }^{9}$ Pues en la elección se firmó también un contrato de dominio en el que se fijaron expresamente los tributos y las cargas que el pueblo aceptaba libremente. Además, con ello el pueblo no ha renunciado a su libertad posterior, pues no se la ha trasladado al rey "sino a la ley", a cuyo imperio también el rey, que "administra al pueblo por medio de las leyes" y es por tanto "un servidor de la ley" (OC: 84), está igualmente sometido. Si el rey quisiera gravar la libertad del pueblo por encima de lo estipulado en el contrato - por ejemplo, por medio de la enajenación de su jurisdicción a terceros, la introducción de nuevos tributos o de una moneda menospreciada-, debería recabar de nuevo el libre consentimiento de todos los tangidos. Poner esta cláusula expresamente en el contrato no era necesario, pues con la ley Blanditus del Codex, las Casas argumenta que "lo

8 Sievernich, Michael, “'Menschenrechte' in der...," op. cit., p. 289.

9 Cfr. Delgado, Mariano, "Die Zustimmung des Volkes in der politischen Theorie von Francisco de Vitoria, Bartolomé de Las Casas und Francisco Suárez", en Grunert, Frank y Seelmann, Kurt (eds.), Die Ordnung der Praxis. Neue Studien zur Spanischen Spätscholastik, Tübingen, Niemeyer, 2001, pp. 157-181. 
que está implícito ni se aumenta ni disminuye, aunque no se diga expresa y declaradamente" (OC 12: 62/63). Y con otra ley, también del Codex, que Las Casas, por cierto, interpreta a su manera, recalca la necesidad del libre consentimiento de todos cuando el príncipe pretenda gravar la libertad del pueblo: id quod est omnibus profuturum de consensu omnium est agendum, se lee en la ley Quicumque. Las Casas la reformula así: id quod est omnibus profuturum, et potest esse nocivum, de consensu omnium est agendum (OC 12: 64/65). Si en asuntos que pueden aprovechar o perjudicar a todos, el rey actúa contra el libre consentimiento del pueblo o lo obtiene 'por coacción', peca contra el derecho natural y el derecho divino (cfr. OC 12: 84/85). Así pues, recabar el libre consentimiento de todos los tangidos es para Las Casas una condición permanente del buen gobierno.

La teoría expuesta en De regia potestate de forma universal, la encontraremos también en los escritos lascasianos sobre el contexto colonial. El hecho de que Las Casas, a diferencia de Vitoria, se refiera tanto a la bula Inter cetera de Alejandro VI (del 4 de mayo de 1493) no tiene que ver con una presumible tendencia hierocrática o medieval en su pensamiento, sino más bien con estas razones: en primer lugar, porque Las Casas ve en el nexo entre translatio imperii y el mandato evangelizador, que hace la bula según su interpretación, un buen argumento para deducir que los derechos de dominio de los reyes de Castilla y León dependen de la premisa de la evangelización pacífica; en segundo lugar, porque a pesar de las razones expuestas por Vitoria (Papa non est dominus civilis aut temporalis totius orbis, loquendo proprie de dominio et potestate civili [...] Summus Pontifex, quamvis haberet potestatem saecularem in mundum, non posset eam dare principibus saecularibus [...] Papa habet potestatem temporalem in ordine ad spiritualia [...] Papa nullam potestatem temporalem habet in barbaros indos neque in alios infideles $)^{10}$ la bula siguió siendo $-\mathrm{y}$ lo seguiría siendo hasta la independencia de Hispanoamérica - el principal argumento de los teólogos y juristas reales para justificar el dominio de España en el Nuevo Mundo, basado sobre todo en un ius belli sacado de la bula, si los pueblos amerindios rechazan la concesión papal. Ante esta situación, Las Casas, bajo lo que hoy denominamos las condiciones históricas de Normal-scien$c e$, intenta interpretar la bula de forma que no justifique de ninguna manera un ius belli. Comienza a perfilar su teoría en los memoriales de 1542 para conseguir las Leyes Nuevas y alcanza la fórmula final en sus dos tratados

10 Vitoria, Francisco de, Relectio de iure belli o paz dinámica, Luciano Pereña (ed.) et al., Madrid, CSIC, 1981, pp. 279-285 (cfr. también su Relectio de indis, I 2, pp. 5-8). 
sobre la cuestión peruana, De Thesauris y Doce dudas, escritos entre 1561 y 1563 y que él mismo llama su "testamento" y su "codicilo" (OC 11.2: 218). Al final del camino nos encontramos con que Las Casas intenta conjugar la bula con la teoría moderna de la soberanía popular.

En la primera mención de la bula, que tiene lugar en la famosa carta magna al Consejo de Indias de 1531 (OC 13: 65-80), Las Casas se limita a recordarle al Consejo que el ingressus y progressus de los españoles en el Nuevo Mundo a través de conquistas y encomiendas no concuerda con el texto de la bula papal, que no contiene ningún permiso para guerras de conquista ni para la esclavitud. Pero que la bula contiene una translatio imperii en favor de los reyes de Castilla y León, y que ésta adquiere todo su valor jurídico 'automáticamente' después del libre bautismo de los indios no presenta todavía un problema para Las Casas. En los memoriales de 1542 (OC 13: 101-131) busca ya una forma de conjugar esa translatio imperii con el derecho natural de dominio que poseen los reyes y señores de los pueblos amerindios. En estos memoriales aparecen ya expresiones como "jurisdicción particular" de los señores amerindios y "jurisdicción suprema y universal" de los reyes de Castilla y León, de forma análoga a la relación entre duques, reyes y el emperador en Europa. También utiliza Las Casas ya aquí la distinción entre potestad in potentia e in actu. Pero sigue defendiendo el 'automatismo' entre libre bautismo y translatio imperii.

La próxima fase está marcada por la controversia con Sepúlveda. En sus Avisos para confesores (OC 10: 360-388), Las Casas ya había dejado claro en 1546 que el dominio español en el Nuevo Mundo estaba falto de legitimidad, pues el ingressus y el progressus habían tenido lugar contra todo derecho natural y de gentes, así como también contra el derecho divino. Ante la acusación de alta traición y herejía, hecha por Sepúlveda, Las Casas se apresurará a escribir las Treinta proposiciones (OC 10: 200-214) y el Tratado comprobatorio (OC 10: 394-543), donde con argumentos teológicos y jurídicos intentará hacer plausible la tesis esbozada en los memoriales de 1542, pero continuará defendiendo el automatismo entre bautismo y translatio imperii, lo que Sepúlveda aprovechará en la controversia de Valladolid (1551) para resaltar la siguiente contradicción: "Pues decir, como dice, que no se han de subjectar al principio, sino después de hechos cristianos, va fuera de toda razón [...] conceder que después de hechos cristianos se han de subjectar a los reyes de Castilla con sus primeros príncipes, es contradecir todo lo que ha dicho para evitar la guerra" (OC 10: 146s). En la respuesta a la duodécima objeción de Sepúlveda durante dicha controversia, Las Casas no ha encontrado todavía la fórmula necesaria, pero lo hará poco 
después en lo que Vidal Abril Castelló ha llamado "La revolución de la duodécima réplica". ${ }^{11}$ Efectivamente, en un texto de 1552, Las Casas pone en cuestión por primera vez el automatismo entre bautismo y translatio imperii:

Y en caso que después de cristianos no quisiesen el tal supremo señor recebir y obedecer $[\ldots]$, no se sigue por eso que se les puede hacer guerra $[\ldots] \mathrm{La}$ razón es porque siempre se ha de tener respeto al fin e causa final por el cual el tal supremo e universal señor se les pone, que es su bien e utilidad [...] $\mathrm{Y}$ en este sentido entiendo y declaro e limito la decimonona proposición de mis treinta proposiciones, donde digo que son obligados los reyes e señores e comunidades de aquel orden de las Indias a reconocer por señores soberanos, monarcas y emperadores a los reyes de Castilla. (OC 10: 185s)

Esa renuncia al automatismo no se refleja en el Tratado comprobatorio, impreso también en 1552. Pero en De Thesauris aprovecha la oportunidad para hacer las correcciones necesarias en su interpretación de la concesión papal:

queremos que se entienda y corrija lo que dijimos en nuestro Tratado comprobatorio del Imperio Soberano [...] 'Pero después de que la fe y babtismo hayan rescibido, tienen los Reyes Católicos su poder perfecto in actu, y pueden usar y ejercer la jurisdicción contenciosa, como en sus súbditos [...]'. A este párrafo debe añadirse lo siguiente: 'después de que hayan prestado su libre consentimiento, según está prescrito' [...] Queremos también que se entienda y corrija lo que dijimos en la XIX Proposición al Consejo Real de las Indias (en nuestro tratado Aqui se contienen treinta proposiciones muy jurídicas). 'Todos los reyes y señores naturales [...] son obligados a reconocer a los reyes de Castilla por universales y soberanos señores y emperadores de la manera dicha, después de haber recibido de su propia voluntad nuestra sancta fe y el sacro bautismo' [...] ahora bien, queremos que este pasaje se entienda del siguiente modo: que tanto después del bautismo como antes, si no quieren admitir a nuestros reyes como príncipes supremos, no hay ningún juez en el mundo que tenga poder para castigarlos por este motivo [...] En efecto, dentro de sus facultades naturales, tienen derecho a consentir o a disentir de la tantas veces citada institución papal, en ambas situaciones en que se encuentren; esto es, o antes o después de su conversión (OC 11/1: 300/301, cap. XXVII).

11 Cfr. Abril Castelló, Vidal, "Los derechos de las naciones...”, op. cit., pp. 15-181 (sobre todo, pp. 121-133). 
La razón del cambio es que Las Casas, después de haber escrito el primer esbozo del tratado De Regia Potestate en 1554, defiende claramente la soberanía popular: "desde el principio, todo principado o régiment político sobre un pueblo tiene su origen en el consentimiento y elección (libres) de dicho pueblo" (OC 11/1: 214s/215s, cap. XVIII). En De Thesauris, Las Casas intenta conciliar precisamente la concesión papal con ese principio universal de soberanía popular y libre consentimiento, es decir, que lo dicho en el Tratado comprobatorio debe entenderse como enmarcado "bajo el orden del derecho natural y divino" (OC 11/1: 246/247, cap. XXII). Pues según el derecho natural, todo señorío necesita del libre consentimiento del pueblo; y de acuerdo con el derecho divino, que — según el conocido axioma escolástico - no suprime dicho derecho natural sino que más bien lo refuerza, el papa sólo puede conceder a los reyes de Castilla y León lo que él mismo en el marco de su limitada potestas indirecta in temporalibus posee sobre los infieles: como máximo un ius ad rem, que antes y después del bautismo sólo se puede convertir en ius in re por medio del libre consentimiento de los pueblos amerindios que son las detentadores naturales de los derechos de soberanía.

El libre consentimiento es, pues, la causa principal y el título más importante para la legitimidad del dominio español (consensus illorum est jus et causa efficiens, principatus Regum nostrorum principalius seu principalior). Sin dicho consentimiento, la institución papal de los reyes de Castilla y León como señores del Nuevo Mundo no tiene ningún valor jurídico (OC 11/1: 316s, 320s, 322s).

Para justificar el libre consentimiento, Las Casas se refiere varias veces, no sin cierta ironía, a la regla del Liber Sextus de las Decretales: Quod omnes tangit, debet ab omnibus approbari (OC 11/1: 198/199, 232/233; OC 11/2: 66/67), resaltando su importancia en la elección de los obispos. Pero también cita leyes de los dos derechos sobre el derecho de adopción, el derecho de elección en los colegios corporativos, el derecho contractual, el derecho de esclavitud o servidumbre, el derecho de aguas y el derecho de arrendamiento ( $c f r$. OC 11/1: 196-237). Encontramos incluso una interpretación de la monarquía de Saúl y David como una institución que depende del libre consentimiento del pueblo, puesto que Dios no quiere violar el derecho natural, que él mismo ha instituído desde un principio como algo bien ordenado e inmutable (cfr. OC 11/2: 70/71ss). Se tiene, pues, la impresión de que Las Casas no desdeña ninguna fuente de la tradición jurídica occidental, si puede apoyar con ella su principio participativo del libre con- 
sentimiento de todos los tangidos, aunque a veces tenga que leer los textos contra el sentido contextual para poder utilizarlos a su favor. ${ }^{12}$

Las Casas quería evitar en el contexto colonial una mayoría que 'venciera' sin miramientos a la minoría, sin tener en cuenta sus derechos. Para la legitimación del dominio español opta por un procedimiento sumamente democrático que tenga en cuenta los vetos o reclamaciones de todos y cada uno de los tangidos. Las Casas se refiere con Baldo explícitamente a "todos aquellos que resultan dañados o a quienes se hace detracción de derecho o a quienes se les causa perjuicio, todos aquellos que, por derecho natural, divino y humano, tienen potestad de consentir o contradecir" (OC 11/2; 68/69). Y con referencia a la ley Si unus del derecho de esclavitud en el Digestum nos da a entender que el consentimiento no se ha logrado, mientras que haya "uno solo" que se sienta ofendido en su derecho: "Si muchos son dueños en común de una finca y quieren constituir en ella una servidumbre, sin contar con uno, necesitarán el unánime consentimiento de todos los dueños. En caso contrario, la falta de uno solo invalida una tal constitución" (OC 11/1: 200/201).

No falta tampoco en el contexto amerindio la referencia al contrato de dominio, del que Las Casas nos dice que es imperiosamente necesario; concuerda con el derecho consuetudinario universal de los pueblos (apud omnes populos et gentes) y no se puede entender como si el rey tuviera mano libre para gravar la libertad de sus súbditos con cargas que sobrepasen lo acordado en él. Para cada nueva carga sería necesario recabar de nuevo el libre consentimiento del pueblo. Incluso si esto no estuviera estipulado expresamente en el contrato, pues es de sentido común (OC 11/1: 306s). Se trata de un contrato recíproco que procede de la voluntad de ambas partes y obliga también a las mismas (Ecce contractus ultro citroque aut ex utraque parte obligatio, ex uoluntate partium consurgens. Ideo dicimus quod pasciscendo diuersas in unum trahimus uoluntates) (OC 11/1: 308s).

Al final de su camino, Las Casas defiende la soberanía popular y el derecho de autodeterminación de forma más universal y clara que Francisco de Vitoria y Francisco Suárez, ${ }^{13}$ convirtiéndose así en un precursor de las teorías constitucionalistas. Las Casas ha desarrollado su teoría política en una época de transición, marcada por grandes cambios, que ya no era el medioevo, sin ser todavía la Edad Moderna. A ello se deben las incongruencias

12 Cfr. Brieskorn, Norbert, "Las Casas und das römische Recht", en Las Casas, WA 3/1, pp. 14-32.

13 Cfr. Delgado, Mariano, "Die Zustimmung des Volkes...", op. cit. 
y contradicciones que a veces encontramos en su obra, y que deberíamos entender "como desarrollo interno de clarificación y maduración de su postura iusnaturalista". ${ }^{14}$

\section{EL DERECHO DE LOS PUEBLOS AMERINDIOS}

A LA RESISTENCIA (CONTRA EL DOMINIO ESPAÑOL, POR SER ÉSTE DESDE UN PRINCIPIO TIRÁNICO)

Junto con su teoría de los sacrificios humanos como un fenómeno "excusable" a la luz de la mera razón natural, separada de la fe y la buena ley positiva, es éste quizá el punto hoy más delicado del pensamiento lascasiano.

La cuestión del tiranicidio no fue sólo discutida intensamente en el siglo XVI, sino ya en el medioevo. El concilio de Constancia, en su sesión 15 del 6 de julio de 1415, condenó en el decreto Quilibet tyrannus la extrema posición del francés Jean Petit (Quilibet tyrannuns potest et debet licite et meritorie occidi per quemcumque vasallum suum vel subditum, etiam per clanculares insidias, et subtiles blanditias et adulationes, non obstante quocumque praestito iuramento seu confoederatione facta cum eo, non exspectata sententia vel mandato iudicis cuiuscumque) como "falsa en la fe y las costumbres $[\ldots]$ herética, escandalosa y allanadora del camino para el fraude, la decepción, la mentira, la traición y el perjurio". El Concilio declara herejes a los que defiendan pertinazmente una doctrina tan "sumamente perniciosa" ${ }^{15}$ En otra declaración posterior se puede leer que, en caso de herejía, el Concilio puede deponer al papa, lo cual puede hacer también el sacro-imperio con el emperador, en caso de que éste cometa graves faltas, pero que las gentes del pueblo no tienen derecho a castigar a sus señores, según su voluntad: "donde lo intentaran hacer, se apropiarían de una potestad de sanción y castigo contra sus Señores que está por encima de ellos". ${ }^{16}$

Al final del siglo XVI, el jesuita Juan de Mariana, en su obra De Rege et Regis institutione (1599) y en medio de los problemas de las guerras de religión en Francia, justificará el asesinato de Henri III (1589) a manos del dominico Jacques Clément, y defenderá así la posición extrema del tiranicidio condenada por el Concilio de Constancia, desacreditando con ello los

14 Pérez Luño, Antonio, op. cit., p. XIV.

15 Denzinger, Heinrich y Hünermann, Peter (eds.), Kompendium der Glaubensbekenntnisse und kirchlichen Lehrentscheidungen, 37a. ed., Friburgo, Alemania, Herder, 1991.

16 Mansi, Joannes Dominicus (ed.), Sacrorum Conciliorum nova et amplissima collectio, Graz, Austria, Akademische Druck- und Verlagsanstalt, 1960, vol. 28, col. 107s. 
esfuerzos de los iusnaturalistas españoles por sacar adelante la teoría de la soberanía popular en los albores del absolutismo. En la constitución Cura dominici gregis del 24 de enero de 1615, el papa Paulo V condenó la posición de Mariana.

El eje de la argumentación de Las Casas es la premisa de que los españoles de las Indias Occidentales son desde un principio tiranos sin justo título, pues han arrancado el dominio a los señores naturales de los pueblos amerindios con engaño y falsedad, con violencia y malicia; es decir, que los españoles son usurpadores y tiranos desde el principio contra quienes los indios pueden librar una guerra justa: "Pues, contra el ímpetu de cualesquiera, tyranos e invasores de reynos agenos y matadores de hombres que ningún mal ni daño les hizieron, ser el remedio la defensión y la resistencia, ninguno lo ignora" (OC 11/2: 126). En este contexto, el pensamiento de Las Casas puede ser malentendido por su aparente radicalidad:

- Por una parte, Las Casas habla de "todos los españoles", aunque piense sólo en los conquistadores y encomenderos, indistintamente como tiranos y enemigos del género humano: en primer lugar porque "todos los españoles" que viven en el Nuevo Mundo o llegan a diario a aquellas tierras, sólo piensan en someter y exterminar a aquellos pueblos con guerras, masacres y asesinatos; y en segundo lugar porque en caso de duda moral existe una conjetura viva y justa contra todos ellos: et universos et ideo sententia bellice iustitie non tenetur discutere an aliqui vel aliqua pars reipublice, sibi hostis injuste, innocens sit, eo quod presumitur tota hostis et totam habet pro hoste et propterea totam damnat et diripit (OC 11/2: 138). Las fechorías de los españoles son para Las Casas tan singulares que "desde el diluvio y pasado acá, no se hallará nación que tanto haya lastimado, diminuido y apocado el linaje humano, y con tan diversas y nuevas maneras de inhumanas crueldades como nosotros havemos hecho en aquellas gentes inocentes en sesenta años" (OC 11/2: 142).

- Por otra parte, Las Casas no concede el derecho de declarar la guerra al tirano/usurpador por su violenta opresión sólo a las dinastías o casas destronadas, sino también a los súbditos, es decir a los indios como personas particulares que pueden así matar a los españoles como si fueran alimañas:

no solamente los señores convocando gentes y ayuntando exército y haziendo guerra pública, y los mismos pueblos adunándose para hazella, pueden justíssimamente a los españoles matar y anihilar sin que dexen memoria dellos, 
pero cualquiera indio particular justíssimamente lo puede hazer por la misma autoridad, durmiendo o velando, por detrás o por delante, o comoquiera que se le ofrezca, como da oportunidad [...] y la causa general, porque cualquiera pueblo o comunidad o reyno puede matar por las dichas maneras al tyrano o tyranos, porque ya son desafiados por toda la república, o tácita o expresamente. (OC 11/2: 132)

Frases como éstas, sacadas de su contexto, pueden hacernos pensar que Las Casas defendía la extrema posición del tiranicidio, condenada por la Iglesia en el Concilio de Constancia. Pero si se estudia con atención a los autores y lugares que Las Casas cita para apoyar su opinión (los dos derechos, Tomás de Aquino, Lucca de Penna, Baldo y Jasón: es extraño que no cite el comentario de Bartolo sobre Digestum 1, 2, 2), no pueden quedar dudas de que permanece en el marco doctrinal del legítimo derecho a la resistencia. La teoría clásica del derecho a la resistencia contra el tiranicidio distinguía entre el usurpador o tirano sin justo título (tyrannus ex defectu tituli) y el señor con legitimidad en origen, pero que se convierte después en tirano (tyrannus quo ad exercitium). Sólo en el primer caso, la resistencia de los particulares puede conducir moralmente al tiranicidio, pues se trataría entonces de una guerra justa. Así lo defiende, por ejemplo, el mismo Francisco de Vitoria en su Dubium de Tyranno, en que evita a la vez cualquier referencia a la situación en las Indias Occidentales. Las Casas, sin embargo, piensa que todo esto vale precisamente para los tiranos españoles en las Indias Occidentales, es decir para los conquistadores y encomenderos, pues no han procedido en su ingressus y progressus con arreglo al derecho, sino sólo por la ley de la fuerza. Las Casas cita a Tomás de Aquino (II Sententiarum, d.44, q.2, q.2, ad 5um) y a Cicerón: quando non est recursus ad superiorem, laudabiliter tyrannus, qui per violentiam et metum se feçit dominum subditis invitis vel ad consensum coactis, occiditur a persona privata (OC 11/2: 132). Pero no se olvida de repetir varias veces, con Tomás de Aquino, dos condiciones para que la resistencia contra los tiranos españoles sea legítima: nisi ex tali occasione, tyranidis maius periculum multitudini venturum timentur, S. Thomas, 2.2 q. 42 a.2 ad 3, nisi fragantur fides promisas quod hosti servandum est, ut iam diximus (OC 11/2: 131, cfr. 132).

El problema en la doctrina lascasiana sobre el tiranicidio no consiste en lo que escribe con tanta crudeza, pues no hace con ello sino aplicar la teoría de la guerra justa - incluída la legitimidad de matar a los españoles en las emboscadas y refriegas - a la causa de los indios. El problema está más bien en la recepción histórica de dicha doctrina. Así, Simón Bolívar y otros 
libertadores de Hispanoamérica, apoyándose en la doctrina de Las Casas, han definido a los españoles colectivamente como "enemigos del género humano", que merecerían ser exterminados de la faz de la tierra. ${ }^{17}$

En Dussel, padre de la filosofía de la liberación, encontramos otra extrapolación de la doctrina lascasiana. Al entregar su "testamento" y su "codicilo" al Consejo de Indias 1564-1566, Las Casas, movido por su santa ira, dice "que las gentes naturales de todas las partes y de cualquiera dellas donde havemos entrado en las Indias tienen derecho adquirido de hazernos guerra justíssima y raernos de la haz de la tierra y este derecho les durará hasta el día del juicio" (OC 11/2: 218). Pero en las Doce dudas, Las Casas precisó que tal derecho a una guerra justa contra los tiranos españoles duraría

hasta el día del juicio [...], si no se interrumpe por alguna de quatro vías: o por paz, o por tregua, o por satisfacción possible de los españoles que hagan a los agraviados, o por remisión que los que rescibieron los daños, de su propia y espontánea voluntad, sin fuerça ni miedo, hagan, con tanto que cessen las injurias y la tyranía y oppressión que de presente sin cessar todos los señores que son bivos y los pueblos padecen. (OC 11/2: 123)

Dussel ignora dichas cláusulas y utiliza el pasaje del testamento lascasiano para dejar bendecir la revolución de Fidel Castro por el padre de los indios: "para Las Casas la guerra de liberación de los indios contra los europeos es - entonces y en nuestros días - una guerra justísima. Las Casas justificaría, por tanto, teológicamente el levantamiento del valiente e intrépido Túpac Amaru (1746-1781) en el Perú o el de Fidel Castro (1959) en Cuba, en la misma Cuba en que tuvo lugar su conversión". ${ }^{18}$

\section{EL DERECHO DE LOS PUEBLOS AMERINDIOS AL RESPETO Y CONSERVACIÓN DE SUS PROPIAS CULTURAS}

La obra lascasiana es una consciente crítica y alternativa a las hermenéuticas indiófobas e hispanocéntricas de quienes no pretendían sino justificar el proceso de expansión colonial, basado en conquistas y encomiendas.

17 Cfr. Delgado, Mariano, Die Metamorphosen des Messianismus in den iberischen Kulturen. Eine religionsgeschichtliche Studie, Schweiz, Switzerland, Immensee Neue Zeitschrift für Missionswissenschaft, 1994, vol. 34, pp. 79-83.

18 Dussel, Enrique, Prophetie und Kritik. Entwurf einer Geschichte der Theologie in Lateinamerika, Friburgo, Suiza, Exodus, 1989, p. 32; cfr. Delgado, Mariano, Abschied vom erobernden Gott. Studien zur Geschichte und Gegenwart des Christentums in Lateinamerika, Schweiz, Suiza, Immensee Neue Zeitschrift für Missionswissenschaft, 1996, p. 291. 
A lo largo de la controversia de Valladolid (1550-1551) con el humanista Juan Ginés de Sepúlveda, que representaba la causa de los conquistadores y encomenderos, es decir de los 'tiranos' en el lenguaje lascasiano, Las Casas comprende la gran importancia del argumento antropológico "no es suficiente con defender los derechos políticos de los pueblos amerindios, sino que, es necesario también defender sus derechos culturales". Las Casas escribe en los años 50 dos obras apologéticas (la Apología en latín y la Apologética historia sumaria en español), para defender los derechos culturales de los pueblos amerindios y defender así también la verdad sobre sus culturas y religiones 19 "como respuesta directa precisamente frente a los argumentos 1, 2 y 4 del autor del Democrates alter". ${ }^{20}$ A la controversia de Valladolid debemos agradecer, pues, no sólo la primera etnografía comparada de la época de los descubrimientos, sino también un nuevo género de literatura apologética. Desde Sócrates se entendía por apología la defensa y justificación de la propia causa ante objeciones y calumnias. Así defienden también los primeros "apologetas" cristianos el cristianismo frente a los argumentos y críticas de los filósofos paganos. Las Casas, sin embargo, escribe sus obras apologéticas para defender la verdad del otro, haciendo así un esfuerzo titánico y sin parangón en la historia de la humanidad de "abogado" de la causa ajena.

En el mismo "argumento" introductorio, destinado a justificar una eventual impresión de la Apologética, nos comunica Las Casas el sentido de su obra, escrita sobre todo para "cognoscer todas y tan infinitas naciones deste vastísimo orbe, infamadas por algunos que no temieron a Dios ni cuánto pesado es ante el juicio divino infamar un solo hombre [...], publicando que no eran gentes de buena razón para gobernarse, carecientes e humana policía y ordenadas repúblicas". Con su Apologética, Las Casas quiere demostrar "la verdad, que es en contrario" (OC 6: 285).

Los calumniadores, de quienes habla Las Casas con frecuencia y no siempre con pelos y señales por aquello de "a buen entendedor [...]", se pueden dividir en dos grupos: al primero pertenecen conquistadores (Hernán Cortés, por ejemplo), misioneros (obispos como el franciscano Juan Cabedo o Quevedo y el dominico Tomás de Ortiz) y cronistas (Gonzalo Fernández de Oviedo) con experiencia directa en el Nuevo Mundo; al se-

19 Cfr. Delgado, Mariano, "Las Casas als "Anthropologe des Glaubens"”, en Las Casas: WA 2, pp. 327-342; id., "Bartolomé de las Casas y las culturas amerindias", Anthropos, Friburgo, Suiza, año CII, 2007, pp. 91-97; id., Stein des Anstoßes. Bartolomé de Las Casas als Anwalt der Indios, St. Ottilien, EOS, 2011.

20 Abril Castelló, Vidal, "Los derechos de las naciones...", op. cit., p. 30. 
gundo grupo pertenecen aquellos que (como el teólogo nominalista de París Juan Mayor, el humanista Juan Ginés de Sepúlveda o el cronista Francisco López de Gómara) no han abandonado Europa, pero utilizan como fuentes los informes del primer grupo.

Las calumnias se basan en un doble prejuicio religioso y civilizador, y hacen de los indios criaturas incapaces del cristianismo, bárbaros incivilizados o 'esclavos de naturaleza'. El prejuicio religioso se refiere naturalmente a la 'idolatría' que según la Biblia es "el principio, la causa y la culminación de todos los males" (Libro de la Sabiduría de la Biblia, capítulo 14, versículo 27) y en los indios parece estar flanqueada además por la sodomía, los sacrificios humanos y el canibalismo, por lo que es absolutamente "inexcusable" (Carta a los Romanos de la Biblia, capítulo 1, versículo 20).

El prejuicio civilizador se basa en la cosmovisión aristotélica: en el "determinismo cosmológico y psicológico", según el cual los seres humanos, la fauna y la flora de determinadas regiones, como por ejemplo, los trópicos, debido a las influencias cósmicas (clima, influencia del cielo, calidad de la tierra, etcétera) no pueden ser sino "inferiores"; y porque los cuerpos de tales seres humanos en comparación con el homo europeus están mal proporcionados, tienen que estarlo también sus espíritus, pues lo uno es reflejo de lo otro, de forma que la armonía exterior y la interior se hallan en íntima dependencia. ${ }^{21} \mathrm{~A}$ pesar de los escritos apologéticos de Las Casas, la tesis de la "inferioridad" de los seres humanos, la fauna y flora de América Latina estará después de moda en los círculos ilustrados (Raynal, Buffon, De Pauw, por ejemplo) del "siglo de las luces". ${ }^{22}$ Incluso el inefable Hegel hablará de la "inmadurez geográfica" del Nuevo Mundo, para caracterizar a renglón seguido a los indios sudamericanos de la siguiente forma: "La inferioridad de esos individuos en todos los aspectos, incluso en el tamaño, es absolutamente evidente". ${ }^{23}$

Pero el humanismo aristotélico partía también de una especie de "determinismo político", según el cual los grupos humanos, que hasta entonces no hubieran logrado una civilización en forma de polis (es decir con labra-

21 Cfr. Pagden, Anthony, La caida del hombre natural. El indio americano y los orígenes de la etnología comparativa, Madrid, Alianza Editorial, 1988, pp. 29-87.

22 Cfr. Gerbi, Antonello, La naturaleza de las Indias Nuevas. De Cristóbal Colón a Gonzalo Fernández de Oviedo, México, Fondo de Cultura Económica, 1992; id., La disputa del Nuevo Mundo. Historia de una polémica 1750-1790, México, Fondo de Cultura Económica, 1982.

23 Hegel, Georg Wilhelm Friedrich, Vorlesungen über die Philosophie der Geschichte, vol. 12: Theorie Werkausgabe, Frankfurt am Main, Suhrkamp, 1970, pp. 107 y 108. 
dores, artesanos, gente de guerra, hombres pudientes, sacerdocio o religión bien ordenada y jueces o buen gobierno) deberían ser considerados como "esclavos de naturaleza", carentes de la capacidad para regirse a sí mismos y por tanto destinados a ser tutelados por otros más inteligentes, a quienes también habrían de servir por su propio bien. ${ }^{24}$

Todos estos calumniadores tenían claro que los indios también eran 'seres humanos'. Esto no fue realmente nunca puesto en duda, aunque lo afirmen los eruditos a la vuelta de nuestros días. La cuestión de Antón Montesino (1511) — ¿Éstos, no son hombres? (OC 5: 1762) — siempre se entendió como si los indios no fueran hombres de la misma clase que el homo europeus, es decir con los mismos derechos y obligaciones, también con las mismas capacidades para la civilización y el cristianismo. Aunque la unidad del género humano no fue puesta seriamente en duda, los indios fueron considerados por muchos como una parte inferior de la humanidad. Lo que conducía no sólo a una justificación de las conquistas y encomiendas por motivos humanitarios y civilizadores, sino también a una pérdida de celo misionero, pues algunos no sólo veían en los indios "siervos de naturaleza", sino que dudaban además de su capacidad para la fe. Sólo si tenemos bien presente este contexto, podemos comprender la tenacidad, perseverancia y fortaleza de Las Casas por demostrar en su Apologética la verdad sobre las religiones y culturas amerindias, una verdad que, para él, "es en contrario", es decir, que los indios son seres racionales, miembros del mismo género humano que nosotros, civilizados y capaces de la fe, e incluso mejor dotados para ésta que muchos pueblos del viejo mundo.

El aspecto más interesante de la Apologética consiste en la "nueva interpretación" de las culturas amerindias que Las Casas consigue, basándose precisamente en las teorías hermenéuticas disponibles en su tiempo. Se puede decir que Las Casas parte de dos constantes antropológicas de valor universal: del deseo natural hacia el verdadero Dios (Tomás de Aquino) y de la naturaleza política del hombre (Aristóteles). Basándose en estos presupuestos, Las Casas interpreta toda clase de "religiosidad" (incluyendo la idolatría y los sacrificios humanos) en clave positiva como expresión de dicho deseo natural hacia el verdadero Dios y no como un fenómeno satánico inexcusable; y detrás de cada cultura amerindia intuye Las Casas un comportamiento racional, con estructuras sociales de una auténtica polis, es

24 Cfr. Aristóteles, Obras, Francisco de P. Samaranch (ed.), Madrid, Aguilar, 1986 (véase, sobre todo, Politica I,2: 1252b; I,8: 1256b; VII,8: 1328b; y Ética nicómaca VI: $1138 \mathrm{~b}-1145 \mathrm{a}$. 
decir una forma de civilización, aunque a primera vista las culturas amerindias nos parezcan "bárbaras".

Mientras que Sepúlveda ${ }^{25}$ opone los "civilizados" europeos a los "bárbaros" indios para justificar el dominio de los primeros sobre los segundos, Las Casas dice que las culturas amerindias son una forma de civilización, si bien diferente de la occidental-cristiana. En este contexto hay que resaltar que Las Casas puede utilizar a Aristóteles para refutar a los 'humanistas aristotélicos' de su tiempo, sólo porque lo subordina al universalismo iusnaturalista y al dogma cristiano de la similitud divina de todo ser humano. En suma: al reinterpretar las culturas amerindias, Las Casas esboza una "antropología de la fe" ${ }^{26}$ bajo la perspectiva escatológica, es decir, teniendo en cuenta que el fin de todo ser humano consiste en haber sido creado para la salvación, provisto para ello por la (sabia y suave) divina providencia de conocimiento racional y libre albedrío.

Todos los seres humanos se hallan por tanto ab initio dentro de un proceso histórico hacia la "civilización" y la "fe". Las diferencias empíricas, es decir, el por qué unos alcanzan esa meta antes que otros, se deben en esta antropología evolutiva a causas "histórico-culturales" y no a determinismos naturales. De no ser así, se habría equivocado la providencia divina, que en principio ha dotado a todos los seres humanos con lo necesario para su salvación: con capacidad racional y libre albedrío. Con ayuda de Cicerón y de Tomás de Aquino proclama Las Casas su "antropología de la fe" en el siguiente manifiesto:

Así que todo linaje de los hombres es uno y todos los hombres, cuanto a su creación y a las cosas naturales, son semejantes y ninguno nace enseñado. [...] Todas las naciones del mundo tienen entendimiento y voluntad y lo que de ambas potencias en el hombre resulta, que es el libre albedrío, y, por consiguiente, todas tienen virtud y habilidad o capacidad e a lo bueno inclinación natural para ser doctrinadas, persuadidas y atraídas a orden y razón y a leyes y a la virtud y a toda bondad. (OC 7: 537)

Se puede considerar esto un "deseo piadoso", una "utopía ingenua", falsificada a diario por la cruda realidad del mal. Pero ello no convierte el manifiesto lascasiano en algo absurdo, como tampoco los continuos atropellos

25 Cfr. Sepúlveda, Juan Ginés de, Demócrates segundo - o De las justas causas de la guerra contra los Indios, 2a. ed., Ángel Losada (ed.), Madrid, CSIC, 1984.

26 Cfr. Delgado, Mariano, "Las Casas als "Anthropologe des Glaubens"”, op. cit.; id., "Bartolomé de las Casas y las culturas amerindias", op. cit. 
de los derechos humanos significan que la Declaración Universal de los Derechos Humanos carezca de sentido. Lo importante es que Las Casas, recurriendo al iusnaturalismo universalista y a la teología cristiana de la creación, defiende de forma paradigmática una visión del ser humano (de todo ser humano) que, en principio, concede a cada cultura dentro de la comunidad universal un puesto en condiciones de igualdad. Esta visión de la humanidad es la condición fundamental de un orden mundial postcolonial y solidario como el que se intenta construir hoy (por lo menos al nivel de las declaraciones de principios).

Empero, conviene también resaltar que la Apologética no está libre de una "idealización compensadora" de las culturas amerindias, pues Las Casas no sólo se limita a desmontar las calumnias de los humanistas aristotélicos con argumentos empíricos objetivos, sino que se empeña siempre en demostrar lo "contrario": que los indios (de las altas culturas) son incluso políticamente más prudentes y están mejor capacitados para una auténtica vida cristiana que los habitantes del Viejo Mundo. En suma: opone a la calumnia la idealización y se convierte así en una fuente importante para los "indigenistas" y "nativistas" contemporáneos.

Esto nos conduce a la pregunta de si Las Casas - al sustituir el prejuicio negativo de los detractores indiófobos por un prejuicio positivo como abogado de la causa indígena - prefigura el mito ilustrado del "buen salvaje", como dicen no pocos investigadores. ${ }^{27}$ Pero esto sólo se puede afirmar, si se distingue bien entre el "buen indio" de Las Casas y el 'buen salvaje' de los ilustrados: Mientras al último no le falta nada, Las Casas, con todo su primitivismo renacentista, ve en la fe cristiana una "perfección" necesaria de la naturaleza humana, incluída la de los pueblos amerindios. También en este punto es, por tanto, un "antropólogo de la fe" de talante 'tomista': sabe que la gracia divina no destruye la naturaleza humana, sino que la presupone y perfecciona (gratia supponit naturam / gratia perficit, non destruit naturam).

27 Cfr. Abellán, José Luis, "Los orígenes españoles del mito del 'buen salvaje'. Fray Bartolomé de las Casas y su antropología utópica”, Revista de Indias, Madrid, año XXXVI, 1976, pp. 157-179 (también véase en id., Historia crítica del pensamiento español, vol. 2: La edad de oro, 2a. ed., Madrid, Espasa-Calpe, 1986, pp. 407-428); Losada, Ángel, "Consideraciones sobre la teoría del 'buen salvaje' y sus fuentes españolas de los siglos XVI y XVII, en especial Colón, Mártir de Anglería, Las Casas, Vives, Guevara y Coreal”, Atti del Secondo Convegno Internazionale di Studi Americanistici, Génova, Associazione Italiana Studi Americanistici, 1980, pp. 549-593; Maravall, José Antonio, "Utopía y primitivismo en Las Casas", Revista de Occidente, Madrid, núm. 141, 1974, pp. 311-388. 


\section{El DERECHO DE LOS PUEBLOS AMERINDIOS AL RESPETO \\ DE SU RELIGIOSIDAD Y A CONSERVAR, DESPUÉS DE LA CONVERSIÓN, LOS ELEMENTOS COMPATIBLES CON EL CRISTIANISMO}

Ya se dijo más arriba que Las Casas interpreta las religiones amerindias de forma positiva como expresión del desiderium naturale por el verdadero Dios. Su visión de la idolatría y de los sacrificios humanos como fenómenos naturales es también parte de su estrategia para desmontar todos los argumentos utilizados por los españoles para justificar las guerras de conquista como guerras justas; pues el partido acusador se refería a la Carta a los Romanos de la Biblia, capítulo 1, versículos 18-21, para demostrar la 'inexcusabilidad' de los indios, es decir, que no tenían "apología" o defensa posible, y que los españoles no eran sino los instrumentos de la cólera de Dios. Las Casas quiere mostrar que los pueblos amerindios tienen sus razones para practicar los sacrificios humanos, la antropofagia y la idolatría, siendo por ello "excusables", por lo menos ante la justicia humana. Su visión de la idolatría como una expresión descarrilada del desiderium naturale por el verdadero Dios se puede apoyar en la tradición teológica, mientras que su interpretación de los sacrificios humanos y de la antropofagia representa algo nuevo y "extraño".

A los que afirman que adorar "piedras" en lugar del Dios verdadero va contra la razón natural, Las Casas les responde con sentido común, que la auténtica intención de los idólatras no consiste en adorar piedras, sino en presentar su reverencia ante el creador por medio de esas "piedras" y de otras manifestaciones del poder divino, con arreglo al conocimiento de Dios que ellos posean. La auténtica intención de los idólatras consiste, pues, en adorar al verdadero Dios, del que por medio de la razón natural sólo pueden saber "que" existe, sin poder decir "en qué" consiste su esencia. Así, bajo la idolatría se esconden sobre todo formas auténticas de religiosidad, y no manifestaciones del demonio.

Para Las Casas, los sacrificios humanos y la antropofagia no dejan de ser una "bestialidad repugnante". Pero al mismo tiempo considera esos fenómenos como algo natural, tanto en el Viejo como en el Nuevo Mundo, cuando falta la luz de la fe y del buen gobierno cristiano. Se trata de una de las tesis más extrañas de su apología de la religiosidad amerindia $-\mathrm{y}$ Las Casas es consciente de la novedad de su pensamiento-, según él mismo escribe a los dominicos de Chiapa y Guatemala en 1564 (cfr. OC 13: 355). Como todos los hombres, movidos por la tendencia natural de la razón, anhelan al verdadero Dios e intentan adorarlo con lo mejor que tienen, y la persona humana precisamente es el mejor de todos los bienes, habría que partir de una recta intención en los sacrificios humanos de los indios. 
Además, los indios creen que el bien y la felicidad de sus repúblicas dependen de los sacrificios humanos, por lo que no es extraño que, dentro de su cosmogonía, ofrezcan a Dios, para apaciguarlo, lo que consideran ser para él lo más valioso y agradable. La práctica de los sacrificios humanos en el Antiguo Testamento, en la Antigüedad occidental, e incluso en la España precristiana, debe ser interpretada también dentro de dicha lógica ( $c f r$. OC 9: 414-463; OC 5 y OC 6).

Con esa interpretación de los sacrificios humanos, Las Casas quería evitar que sirvieran de excusa para las guerras de conquista, pues en la controversia sobre los justos títulos, el argumento de la defensio innocentium ocupaba un lugar preeminente. En su obra tardía De thesauris, Las Casas nos ofrece su última visión sobre el tema, que es un poco más matizada ( $c f r$. OC 11/1: 432-439): Si los indios después de una reiterada exhortación continúan practicando los sacrificios humanos y la antropofagia, matando para ello a inocentes, se podría entonces obligarlos a abandonar dichas prácticas haciendo uso de una moderada coacción. Pero la intervención sólo podría ser legítima para defender a los inocentes y no para castigar a los indios por esas prácticas, para nosotros criminales e inhumanas, o para someterlos como esclavos y despojarlos de sus bienes. Y antes de dicha intervención humanitaria, habría que sopesar bien si el número de inocentes, que serían víctimas de la misma, no resultaría mayor que el número de los que se intenta salvar de la muerte injusta. Y hay que valorar, además, si el escándalo que produciría necesariamente la intervención, al final no sería un impedimento gravísimo para la aceptación del mensaje cristiano. De ser así, sería mejor desistir de dicha liberación de los inocentes, pues actuaríamos contra la regla racional que nos incita a elegir el mal menor. Y como Las Casas, a fin de cuentas, cree que los sacrificios humanos de los indios son ese mal menor, comparados con las guerras de conquista de los españoles, recomienda, pues, tolerarlos junto a la idolatría hasta que puedan ser superados al convencer su entendimiento con argumentos racionales y por la suave atracción y exhortación de la voluntad con buenos ejemplos, es decir, hasta que se consiga que los indios se conviertan libremente al cristianismo.

La apología de la religiosidad amerindia hecha culmina en la afirmación de que los cristianos podrían aprender de la misma, si se dejan de lado los sacrificios humanos. En su descripción de la religión de los aztecas, Las Casas nos dice:

Y en tanto grado eran todos los actos y obras que en el culto de sus dioses hacían honestos y decentes y de toda vileza, fealdad y deshonestidad desnudos y limpios que, quitados los sacrificios horrendos y sangrientos que ofrecían, 
que nuestra religión christiana y ley dulce y suave de Jesuchristo prohíbe, y algunas cerimonias y actos que parecía[n] enderezarse a los ídolos, todo lo demás de hacerse y complirse dentro de nuestra universal iglesia y aprenderse dellos era dignísimo. (OC 8: 1255)

Para Las Casas, el cristianismo es naturalmente la religión verdadera. Pero con su descubrimiento de una "religiosidad auténtica" bajo la idolatría, así como con su rechazo de un cristianismo que occidentalice completamente las culturas amerindias, Las Casas es un precursor de lo que hoy llamamos una auténtica inculturación. No se le puede pedir conocer la profunda problemática de la teología moderna de las religiones, pero hay que constatar que su visión de la evangelización y de las religiones y culturas amerindias se acerca mucho a lo que dice el Concilio Vaticano II en su Declaración sobre las religiones no cristianas Nostra aetate (no. 2): "La Iglesia católica no rechaza nada de lo que en estas religiones es verdadero y santo. Considera con sincero respeto los modos de obrar y de vivir, los preceptos y doctrinas que, aunque discrepen mucho de los que ella mantiene y propone, no pocas veces reflejan, sin embargo, un destello de aquella Verdad que ilumina a todos los hombres". ${ }^{28}$

\section{EL DERECHO DE LOS PUEBLOS AMERINDIOS A RECHAZAR UN CRISTIANISMO PREDICADO A LA SOMBRA DE LAS ARMAS}

La tesis de Las Casas sobre la única norma de evangelización compatible con el cristianismo es una loa a la libertad sin coacción y una crítica implacable de la misión por la fuerza de las armas:

Única, sola e idéntica para todo el mundo y para todos los tiempos fue la norma establecida por la divina Providencia para enseñar a los hombres la verdadera religión, a saber: persuasiva del entendimiento con razones y suavemente atractiva y exhortativa de la voluntad. Y debe ser común a todos los hombres del mundo, sin discriminación alguna de sectas, errores o costumbres depravadas. (OC 2:17)

En la historia del cristianismo nadie ha defendido de forma tan clara y perseverante la evangelización sin coacción.

28 Conferencia Episcopal Española, Concilio Ecuménico Vaticano II. Constituciones, decretos, declaraciones, Madrid, BAC, 1993, p. 702. 
$\mathrm{Al}$ acentuar la evangelización pacífica como la única norma misionera compatible con el cristianismo, Las Casas concede a los no-cristianos los siguientes derechos: el derecho a no querer oir la predicación del Evangelio, sin que ello conlleve desventajas o castigos (cfr. OC 9: 338-351); el derecho de rechazar a los evangelizadores y al Evangelio por la inaudita novedad que representa el mensaje cristiano ( $c f r$. OC 9: 266).

Sólo en un caso estarían obligados los indios a dar crédito a la nueva religión: cuando — como Las Casas dice con Tomás de Aquino (Quodlib. 2, artículo 6) - los oyentes del Evangelio no sólo son movidos por la gracia de Dios y la luz interior, sino que también son convencidos por argumentos y atraídos por hechos extraordinarios o milagrosos (OC 9: 274s, 268-293). Bajo lo último, Las Casas no piensa primordialmente en curaciones milagrosas fuera de las leyes de la naturaleza, como hacen por ejemplo Agustín ${ }^{29}$ y el Concilio Vaticano I; ${ }^{30}$ el mayor milagro es para Las Casas la vida ejemplar de los evangelizadores y de los demás cristianos. Sólo si se dan estas tres condiciones - Las Casas piensa que teniendo en cuenta las circunstancias de la evangelización a la sombra de las conquistas y encomiendas, la tercera condición es prácticamente imposible-y los indios, sin embargo, rechazaran el cristianismo como la verdadera religión, podríamos decir que son "inexcusables". Pero también en ese caso sería imposible distinguir con medios humanos entre los "inexcusables" y los "excusables", de forma que deberíamos dejar la decisión — siguiendo el ejemplo de la parábola del trigo y la cizaña (Mateo 13,24-30), que en la Europa de la época era citada también por los defensores de la libertad de conciencia- al juicio divino. Así, el pecado de la idolatría es para Las Casas, a fin de cuentas, algo que compete solamente a Dios y al pecador, no a la jurisdicción humana, ni civil ni eclesiástica (OC 9: 276-281).

La argumentación de Las Casas conduce prácticamente - en el siglo XVI - a la evangelización pacífica defendida en el Decreto Ad gentes del Concilio Vaticano II, y a la prohibición de toda coacción según el principio de libertad religiosa defendido por el mismo Concilio en la Declaración Dignitatis humanae (núm. 2):

Esta libertad consiste en que todos los hombres deben estar libres de coacción, tanto por parte de personas particulares como de los grupos sociales y de cualquier poder humano, de modo que, en materia religiosa, ni se obligue

29 Cfr. De Civitate Dei, lib. XXII, cap. 8.

30 Denzinger, Heinrich y Hünermann, Peter (eds.), op. cit., núm. 3009. 
a nadie a actuar contra su conciencia, ni se le impida que actúe conforme a ella, pública o privadamente, solo o asociado con otros, dentro de los debidos límites. ${ }^{31}$

\section{CONSIDERACIONES FinALES}

De lo dicho se desprende la importancia de Las Casas para el discurso actual sobre los derechos humanos y su universalización. Las Casas, que ha sido un hombre "muy leído y docto en todas las buenas letras", ${ }^{32}$ defiende en la época de los descubrimientos cinco derechos fundamentales de los hombres y pueblos amerindios, y lo hace con insistente perseverancia, celo apologético y sabios argumentos: el derecho a la aceptación pacífica y libre del dominio español; el derecho a la resistencia armada contra el dominio español ilegítimo y tirano; el derecho al respeto y a la conservación de sus culturas; el derecho al respeto de su religiosidad y a la conservación, después de la conversión, de los elementos compatibles con el cristianismo; y finalmente el derecho a rechazar un cristianismo predicado a la sombra de la conquista colonial.

También hoy, la universalización de los valores de la cultura occidental sólo podrá hacerse con posibilidades de éxito, respetando dichos derechos fundamentales y abogando por un auténtico universalismo globalizado ${ }^{33}$ que tenga en cuenta los valores universalizables de las otras culturas. En este sentido, Bartolomé de Las Casas, el profeta que criticó la primera fase de globalización en el siglo XVI "como si fuera un indio" ("si Indus esset", OC 9: 604) y nos abrió los ojos para percibir los valores de las culturas y religiones amerindias, es una voz imprescindible en nuestros días, es nuestro contemporáneo, y, como decía Gabriela Mistral, "una honra del género humano". 34

\section{BIBLIOGRAFÍA}

\section{Obras de Bartolomé de Las Casas}

Las Casas, Bartolomé de, Obras completas, Paulino Castañeda Delgado (ed.), Madrid, Alianza Editorial, 1988-1998, 14 vols. (abreviación: OC con número de volúmen y página).

31 Conferencia Episcopal Española, op. cit., p. 659.

32 Mendieta, Jerónimo de, Historia eclesiástica indiana, Madrid, Atlas, 1973, vol. 2, p. 13.

33 Cfr. Wallerstein, Immanuel, op. cit.

34 Mistral, Gabriela, Escritos políticos, México, Fondo de Cultura Económica, 1994, p. 195. 
Las Casas, Bartolomé de, Werkauswahl, Mariano Delgado (ed.), Paderborn, Ferdinand Schöningh, 1994-1997, 4 vols. (abreviación: WA con número de volúmen y página).

\section{Bibliografía secundaria}

Abellán, José Luis, "Los orígenes españoles del mito del 'buen salvaje'. Fray Bartolomé de las Casas y su antropología utópica", Revista de Indias, Madrid, año XXXVI, 1976 (también véase en id., Historia crítica del pensamiento español, vol. 2: La edad de oro, 2a. ed., Madrid, Espasa-Calpe, 1986).

Abril Castelló, Vidal, "Los derechos de las naciones, según Bartolomé de las Casas y la Escuela de Salamanca", en LAS CASAS, OC 6.

Abril Castelló, Vidal, "Los teólogos-juristas de la Escuela de Salamanca, padres de los derechos humanos en el mundo moderno y contemporáneo (planteamiento y proyección)", Religión y Cultura, Madrid, año XLIV, núm. 205, 1998.

Aristóteles, Obras, Francisco de P. Samaranch (ed.), Madrid, Aguilar, 1986. Beuchot, Mauricio, Los fundamentos de los derechos humanos en Bartolomé de las Casas, Barcelona, Antrhopos, 1994.

BRIESKORN, Norbert, "Las Casas und das römische Recht", en LAS CASAS, WA 3/1. Comisión NaCional PaRa la CONMEMORACión del V CENTENARIo del DesCUBRIMIENTO DE AmÉRICA, Declaración universal de los derechos humanos. Homenaje a Fray Bartolomé de Las Casas, Sevilla 1484, Madrid, Ministerio de Cultura-Junta de Andalucía, 1984.

Conferencia Episcopal Española, Concilio Ecuménico Vaticano II. Constituciones. decretos, declaraciones, Madrid, BAC, 1993.

Delgado, Mariano, Die Metamorphosen des Messianismus in den iberischen Kulturen. Eine religionsgeschichtliche Studie, Schweiz, Suiza, Immensee Neue Zeitschrift für Missionswissenschaft, 1994.

Delgado, Mariano, "Las Casas als 'Anthropologe des Glaubens"”, en LaS CASAS, WA 2.

Delgado, Mariano, Abschied vom erobernden Gott. Studien zur Geschichte und Gegenwart des Christentums in Lateinamerika, Schweiz, Suiza, Immensee Neue Zeitschrift für Missionswissenschaft, 1996.

Delgado, Mariano, "Universalmonarchie, translatio imperii und Volkssouveränität bei Las Casas oder Das prozeßhafte Entstehen einer politischen Theorie zwischen Mittelalter und Neuzeit", en LAS CASAS, WA 3/1. 
Delgado, Mariano, "Die Zustimmung des Volkes in der politischen Theorie von Francisco de Vitoria, Bartolomé de Las Casas und Francisco Suárez", en Grunert, Frank y Seelmann, Kurt (eds.), Die Ordnung der Praxis. Neue Studien zur Spanischen Spätscholastik, Tübingen, Niemeyer, 2001.

Delgado, Mariano, Stein des Anstoßes. Bartolomé de Las Casas als Anwalt der Indios, St. Ottilien, EOS, 2011.

Delgado, Mariano, "Bartolomé de las Casas y las culturas amerindias", Anthropos, Friburgo, Suiza, año CII, 2007.

Delgado, Mariano (ed.), "Ces gens ne sont-ils pas des hommes?" - Evangile et prophétie / "Sind sie etwa keine Menschen?" - Evangelium und prophetie. Colloque de la Faculté de Théologie de Fribourg (1-4 décembre 2011) - Kolloquium der Theologischen Fakultät Freiburg (1.- 4. Dezember 2011), Friburgo, Suiza, Academic Press, 2013.

"Dem Vorkämpfer der Menschenrechte Fray Bartolomé de Las Casas 15661966”, Neue Zeitschrift für Missionswissenschaft, año XXII, núm. 3, Immensee, 1966.

Denzinger, Heinrich y Hünermann, Peter (eds.), Kompendium der Glaubensbekenntnisse und kirchlichen Lehrentscheidungen, 37a. ed., Friburgo, Alemania, Herder, 1991.

Dussel, Enrique, Prophetie und Kritik. Entwurf einer Geschichte der Theologie in Lateinamerika, Friburgo, Suiza, Exodus, 1989.

EgGensperger, Thomas, Der Einfluss des Thomas von Aquin auf das politische Denken des Bartolomé de Las Casas im Traktat De imperatoria vel regia potestate. Eine theologisch-politische Theorie zwischen Mittelalter und Neuzeit, Münster, Lit, 2000.

Fernández de Sotomayor, Juan, Catecismo o instrucción popular, Cartagena de Indias, Manuel González y Pujol, 1814.

Galmes, Lorenzo, Bartolomé de las Casas: defensor de los derechos humanos, Madrid, Católica, 1982.

Gerbi, Antonello, La naturaleza de las Indias Nuevas. De Cristóbal Colón a Gonzalo Fernández de Oviedo, México, Fondo de Cultura Económica, 1992.

Gerbi, Antonello, La disputa del Nuevo Mundo. Historia de una polémica 1750-1790, México, Fondo de Cultura Económica, 1982.

GiLlner, Matthias, "Bartolomé de Las Casas und die Menschenrechte", Jahrbuch für Christliche Sozialwissenschaften, Münster, 1998, t. 39.

Hanke, Lewis, Bartolomé de Las Casas, pensador politico, historiador, antropólogo, Buenos Aires, Eudeba, 1968.

Hegel, Georg Wilhelm Friedrich, Vorlesungen über die Philosophie der Geschichte, vol. 12: Theorie Werkausgabe, Frankfurt am Main, Suhrkamp, 1970. 
Hernández, Ramón, "Francisco de Vitoria y Bartolomé de Las Casas, primeros teorizantes de los derechos humanos", Archivo Dominicano, Salamanca, año IV, 1983.

Linares MazA, Antonio, Bartolomé de las Casas, un andaluz en el Nuevo Mundo. Desagravio psiquiátrico al primer anticolonialista, precursor de los derechos humanos, Málaga, Arguval, 1993.

LosadA, Ángel, “Consideraciones sobre la teoría del 'buen salvaje' y sus fuentes españolas de los siglos XVI y XVII, en especial Colón, Mártir de Anglería, Las Casas, Vives, Guevara y Coreal", Atti del Secondo Convegno Internazionale di Studi Americanistici, Génova, Associazione Italiana Studi Americanistici, 1980.

LosAdA, Ángel, "La doctrina de Las Casas y su impacto en la ilustración francesa (Voltaire, Rousseau...)", En el quinto centenario de Bartolomé de Las Casas, Madrid, Ediciones de Cultura Hispánica, 1986.

Mansi, Ioannes Dominicus (ed.), Sacrorum Conciliorum nova et amplissima collectio..., Graz, Akademische Druck -und Verlaganstalt, 1960.

Maravall, José Antonio, "Utopía y primitivismo en Las Casas", Revista de Occidente, Madrid, núm. 141, 1974.

Mariana, Juan de, De Rege et Regis institutione, Toleti, Apud Petrum Rodericum Typo Regium, 1599.

Mendieta, Jerónimo de, Historia eclesiástica indiana, Madrid, Atlas, 1973, vol. 2.

Mistral, Gabriela, Escritos políticos, México, Fondo de Cultura Económica, 1994.

Pagden, Anthony, La caída del hombre natural. El indio americano y los orígenes de la etnología comparativa, Madrid, Alianza Editorial, 1988.

Pereña, Luciano, La Carta de los derechos humanos según Bartolomé de las Casas, Guatemala, Convento de Santo Domingo, 1978.

PÉrez LuÑo, Antonio, "Democracia y derechos humanos en Bartolomé de las Casas. Estudio preliminar al tratado De Regia Potestate", en LAs CASAS, OC 12, pp. I-XXXIX.

PiePKe, Joachim, "Die Frage der Menschenrechte im Amerika des 16. Jahrhunderts", Theologie der Gegenwart, Erfurt, 1990.

Roca BAREA, María Elvira, Imperiofobia y leyenda negra. Roma, Rusia, Estados Unidos y el Imperio español, 10a. ed., pról. de Arcadi Espada, Madrid, Siruela, 2017.

Ruiz Sotelo, Mario, Crítica de la razón imperial. La filosofía política de Bartolomé de Las Casas, México, Fondo de Cultura Económica, 2010. 
SCHMid, Peer, "Freiheit und Herrschaft in Las Casas De imperatoria vel regia potestate (1571). Eine propagandistische Finte", Jahrbuch für Geschichte Lateinamerikas, Colonia, núm. 39, 2002.

SepúlvedA, Juan Ginés de, Demócrates segundo - o De las justas causas de la guerra contra los Indios, 2a. ed., Ángel Losada (ed.), Madrid, CSIC, 1984.

Sievernich, Michael, "460 Jahre Menschenrechte", Stimmen der Zeit, Friburgo, Alemania, 2012, vol. 137.

Solís AznAR, Pedro, "Fray Bartolomé de las Casas, precursor de los derechos humanos", Revista de la Universidad de Yucatán, Mérida, año 16, núm. 91, 1974.

Université D'Aix-Marseille et Institut d’Études Politiques, Las Casas et la politique des droits de l'homme, Aix-en-Provence, Institut d'Études Politiques, 1976.

Vitoria, Francisco de, Relectio de iure belli o paz dinámica, Luciano Pereña (ed.) et al., Madrid, CSIC, 1981.

WallersteIn, Immanuel, European Universalism. The Rhetoric of Power, Nueva York, New Press, 2006. 